\title{
Educating for innovation: students' perceptions of the learning environment and of their own innovation competence
}

\section{A. R. Ovbiagbonhia ${ }^{1}$ (D) Bas Kollöffel ${ }^{2} \cdot$ Perry den Brok $^{3}$}

Received: 1 October 2018 / Accepted: 12 February 2019 / Published online: 18 February 2019

(c) The Author(s) 2019

\begin{abstract}
Developing students' innovation competence is becoming increasingly important in higher education, yet few studies have actually investigated whether current learning environments are aimed at promoting this competence and whether students perceive that they have mastered this competence. This study aimed to map students' perceptions of the learning environment in terms of whether their schools' curricula were directed towards developing innovation competence and their perceptions of their own innovation competence. A survey was created and administered to 130 students of Built Environment programs at eight Universities of Applied Sciences in the Netherlands. Students perceived a supportive learning environment for innovation competence only to a limited degree. On the other hand, students rated their own innovation competence moderately highly. Despite positive perceptions of students' own innovation competence, the learning environment was only to a limited degree aimed at developing innovation competence. The results suggest that universities might need to focus more explicitly and structurally on the teaching and assessment of innovation competence.
\end{abstract}

Keywords Innovation competence $\cdot$ Learning environment $\cdot$ Students' perceptions

\section{Introduction}

In recent years, because of the changing work environment and great challenges for society which engineers are expected to address (Craft 2011), many engineering curricula have sought to increase the innovation competence of their students (Beghetto and Kaufman 2013). In the present study, innovation competence is defined as the capacity to generate original, appropriate and implementable solutions to problems (West and Farr 1990).

\section{A. R. Ovbiagbonhia}

a.r.ovbiagbonhia@pl.hanze.nl

1 Hanze Universities of Applied Sciences Groningen, PO Box 3017, 9701 DA Groningen, The Netherlands

2 University of Twente, PO Box 217, 7500 AE Enschede, The Netherlands

3 Wageningen University \& Research, P.O. Box 8130, 6700 EW Wageningen, The Netherlands 
The capacity to innovate is considered central to many higher education domains and is defined as a core competence for a 21st century engineer (Beghetto and Kaufman 2013; Chan and Yuen 2014; Craft 2011; Robinson 2011; Wagner 2010). Innovation competence has been identified as an important learning goal in higher education in general (Beghetto and Kaufman 2013; Chan and Yuen 2014), particularly in Built Environment (the umbrella term for departments and areas of expertise such as Architecture, Building Technology, Building Management, Civil Engineering, Landscape and Urban Planning).

In response to society's growing need for professionals with strong 21 st century skills, many educational institutions are looking for ways to foster the innovation competence of their students (Richardson and Mishra 2018; Robinson 2011; Wagner 2010). Environments that support the development of innovation competence are less structured and more hands-on, represent multiple ways of learning, and have a less rigid teachers' role than in traditional learning environments (Dalke et al. 2007). In a learning environment that supports development of innovation competence, learning goals are explicitly articulated, teaching is directed towards realising these goals at both the school and classroom levels and students perceive their learning to become innovative as important for their future personal and career development (Beghetto and Kaufman 2014). Such an environment emphasises the importance of making learning personally relevant for the learner through connecting teaching activities within school to out-of-school experiences by engaging students in authentic tasks (Jonassen 1994; Lim and Sato 2006). Also, in a learning environment that supports innovation competence, students are provided with opportunities to negotiate with teachers, stakeholders and each other about what to learn and how best to learn it (Burgess and Addison 2007; Rutland and Barlex 2008). Finally, in environments that support the development of innovation competence, students learn about the uncertainty of scientific knowledge and that scientific knowledge is evolving, is created through theorydependent learning, involves human experiences and values, and is socially and culturally determined (Fraser 2012).

According to Beghetto (2010), there is tremendous interest in developing innovation competence in educational settings and, as a result, the number of studies focusing on this has grown. However, not much is known about how students perceive learning environments intended for innovation competence development (Beghetto and Kaufman 2014). Much of the previous research in the field of innovation competence has focused mainly on individual, psychological and/or personality variables in relation to innovation competence, which is very important but offers minimal practical advice to teachers (Beghetto 2010). Learning environments intentionally designed to develop innovation competence and students' perceptions of competence have not received much attention in the educational research literature (Beghetto and Kaufman 2014; Richardson and Mishra 2018).

It is critical to investigate students' perceptions of their learning environments, especially in higher education, given the limited research in this sector. While many teachers might believe that developing students' innovation competence is relevant, they could lack the know-how to do so (Chan and Yuen 2014). Research on learning environments has also demonstrated a link between students' perceptions of the learning environment and their learning outcomes, with students' perceptions predicting an appreciable amount of variance in outcomes (Dorman and Fraser 2009). Therefore, investigating students' perceptions of the learning environment is a valid way to improve learning outcomes (Fraser 2012).

Understanding students' views about features of the learning environment is critical in fostering students' innovation competence, because previous research has revealed that the learning environment is an important variable that affects student learning in general (Aldridge and Fraser 2011; Fraser 2007, 2012) and their innovation competence 
development more particularly (Chan and Yuen 2014). To improve our understanding of how to support students' development of innovation competence and in turn support teachers to create a supportive learning environment for such development, an important step is to understand how students perceive the learning environment with regard to development of innovation competence at the school and classroom levels.

Past studies in the domain of learning environments have demonstrated the effectiveness of using learning environment variables in the evaluation of educational programs (Bell and Aldridge 2014; Martin-Dunlop and Fraser 2008). However, our review of the literature suggests that there have been no studies that have examined students' perceptions of a learning environment directed at innovation competence in general, and in the domain of Built Environments in particular. Therefore, this study aimed to fill this gap in the literature and to extend research in the field of learning environments by measuring students' self-perceived innovation competence and their perceptions of features of existing learning environments aimed at innovation competence, as well as investigating the association between these two elements.

In the next section, we describe briefly the concept of innovation competence, the components of innovation competence and, finally, the characteristics of a supportive learning environment for developing innovation competence.

\section{Conceptual framework}

\section{Creativity, innovation and innovation competence}

While creativity is the generation of novel, unique and useful creative ideas, innovation involves the successful implementation of creative ideas, products, services, procedures, theories and strategies (West and Farr 1990). This implies that, before people can become innovative, they need to be skilled in identifying performance gaps where innovative solutions are needed, in generating creative ideas and in transforming these creative ideas into realistic, practical and marketable solutions (Bel 2010). Innovation competence is, therefore, the capacity to develop creative ideas that can be implemented successfully as products, services, procedures, theories and strategies that are useful or meaningful to the intended audience (Tidd and Bessant 2009). Innovation competence, like any competence, involves the integration of knowledge, skills and attitudes. Innovative individuals have been reported as having a high level of creative and leadership abilities, persistence and task motivation, creative self-efficacy, propensity to take calculated risks and liking for working on ambiguous and complex problems (Chell and Athayde 2009; Hurt et al. 1977; Tierney and Farmer 2002).

The literature is quite elaborate about the components of innovation competence that should be developed, and several conceptual descriptions of innovation competence exist, which vary tremendously (Chell and Athayde 2009; Dyer et al. 2009; Hurt et al. 1977; Tierney and Farmer 2002). Similarly, many studies have been devoted to different groups or contexts for innovation, such as firms and organisations, (Scott and Bruce 1994) or consumers (Hurt et al. 1977; Price and Ridgeway 1983). These studies were sometimes very generic (Hunter et al. 2012; Jackson and Messick 1967) and sometimes very specific to designated domains, such as engineering (Dyeret et al. 2009; Fisher et al. 2011; Keller 2012; Ragusa 2011), or types of education, such as secondary education (Chell and Athayde 2009). From the literature, six interrelated components of innovation competence 
come to the fore: creativity, leadership, creative self-efficacy, energy, risk propensity and ambiguous problem-solving. For the purposes of clarity, we discuss the elements individually, but in practice they are interconnected.

\section{Creativity}

Researchers regard creativity as a strong component of innovation competence (Chell and Athayde 2009; Hurt et al. 1977). According to Antonietti et al. (2011), after the recognition of a problem or an area where an innovative solution is needed, that idea needs to be further developed by the integrated processes of widening, connecting and restructuring. Widening means: keeping an open mind; being aware of the great number of elements that can be identified in a given situation; recognising possible, not obvious, meanings; discovering hidden aspects; and overcoming apparent constraints. Connecting entails the capacity to establish reciprocal relationships among different elements, such as by thinking in scenarios, drawing analogies between remote things, combining ideas in odd ways and synthesising a multiplicity of disparate elements into an overall structure. Restructuring involves looking at problems or solutions from different perspectives, which can include seeing things differently by inverting relationships between their elements, asking original questions and imagining what should happen if unusual conditions occurr.

\section{Leadership}

Innovation competence is highly dependent on leadership skills because no innovation takes place in isolation (Chell and Athayde 2009; Hurt et al. 1977). Leadership involves having a clear vision of the end goal, networking, collaborating, mobilising, organisational ability and convincing other experts in order to actualise the goal (Dyer et al. 2009).

\section{Creative self-efficacy}

The concept of creative self-efficacy is supported by Bandura's (1997) self-efficacy theory, which describes self-confidence and beliefs about the self in terms of having the required knowledge, skill and ability to perform a specific task. Creative self-efficacy, therefore, is the degree to which a person displays confidence in solving problems creatively (Tierney and Farmer 2002). Previous studies have linked self-efficacy to creative behaviour in individuals (Tierney and Farmer 2011; Wang et al. 2013).

\section{Energy}

Persistence, proactive behaviour and drive have been associated with innovation competence in different studies (Chell and Athayde 2009). To fully develop an innovative idea requires having a clear vision of the end destination which, in turn, requires vigour, commitment, disposition and motivation (Hunter et al. 2012).

\section{Risk propensity}

Real-life problems are often ambiguous, complex and devoid of clear answers. Risk avoidance can result in a person being reluctant to innovate (West 2002). Conversely, people willing to take risk are more likely to be innovative (Tabak and Barr 1999). It takes 
confidence and risk-taking on the part of the innovator to get a creative idea to mature to the implementation or innovation stage (Campbell et al. 2004).

\section{Ambiguous problem-solving}

This concept describes a person's willingness to change and to innovate within a complex and ambiguous network of problems (Hurt et al. 1977; Keller 2012). Consequently, innovation competence could be expressed in one's inclination to be challenged by unanswered questions, ambiguities and unresolved problems (Keller 2012).

The capacity to innovate can be cultivated. However, the role and relevance of a supportive learning environment in this respect must be spelled out. In the next section, we describe what makes such an environment.

\section{Components of learning environments that foster the development of innovation competence}

The context or specific setting (social and cultural) that is intentionally created to support learning is often referred to as an environment, milieu or climate (Fraser 2012). This includes the psychological factors, the classroom teaching, and the physical factors of any place where learning occurs, including virtual and non-traditional spaces (Fraser 2012).

Learning environments that focus on the development of innovation competence start with the recognition of this competence as a key educational goal and an essential 21st century skill that should be supported in schools (Chan and Yuen 2014; Robinson 2011; Wagner 2010). In creating such an environment, a constructivist approach is generally suggested (Ertmer and Newby 1993). In constructivist learning environments, learners are encouraged to actively construct their understanding and make their own representations, instead of receiving information from a teacher. According to Jonassen (1999), in a constructivist learning environment, learners are given tools that enable them to engage in discussion, collaboration and reflection. Constructivist learning environments engage the learner in solving authentic tasks. Because authentic tasks are 'real world' or contextualised tasks that are personally relevant or interesting to the learner (Brookes et al. 2012; Jonassen 1999), they are considered particularly suitable for effective innovation competence development (Li et al. 2012).

Several characteristics of constructivist learning environments that are relevant for promoting innovation competence have been identified. Below, we discuss briefly some relevant characteristics of constructivist learning environments that were emphasised in this study. Subsequently, we discuss some prior research on learning environments in which constructivist learning environments were investigated using the same instrument as in the present study, the Constructivist Learning Environments Survey (CLES; Taylor et al. 1995). The CLES has been used by several researchers, especially in the domain of primary and secondary education, to map students' perceptions of dimensions that constitute a constructivist learning environment, such as uncertainty, student negotiation and personal relevance. The CLES enables educators and researchers to measure students' perceptions of the extent to which constructivist approaches are present in classrooms (Taylor et al. 1997). We selected the CLES for this study because of its proven ability to capture specific dimensions of a constructivist learning environment and because of its demonstrated and strong factorial validity and reliability in numerous countries (Fraser 2012). Before discussing the empirical findings and insights that have been obtained using this instrument, 
we first briefly introduce the specific dimensions it addresses, followed by a discussion of relevant past research.

Personal Relevance is the extent to which the content used in the constructivist learning environment is relevant to students' everyday out-of-school experiences. To foster innovation competence in students, relevance can be promoted through connecting teaching with students' everyday experiences through user-centred design learning and engaging in authentic activities, open-ended tasks and real-world problems (Jonassen 1994; Lim and Sato 2006). It is important that students have the opportunity to engage with real-world problems in the field of study in order to have a rich and meaningful learning experience (Fasko 2001, p. 322).

Uncertainty is the extent to which students are provided the opportunity to experience that innovative knowledge is evolving and that it is culturally and socially determined. This involves teaching students how to explore, collect, analyse and use data to ignite innovation (Dyer et al. 2009; Honebein 1996). Students are made to understand that the process of knowledge creation occurs not only in individual contexts, but also through the interactions involved in social negotiations, collaborations and experiences (Dyer et al. 2009; Jonassen 1994). The literature provides strong evidence that students' innovation competence is enhanced when they are provided opportunities to work collaboratively with each other (Burgess and Addison 2007; Dillon et al. 2007; Halsey et al. 2006; Rutland and Barlex 2008; Wood and Ashfield 2008). Group work and working in teams have been demonstrated to be a relevant feature of innovation-supportive learning environments (Burgess and Addison 2007; Rutland and Barlex 2008).

Student negotiation is the extent to which students and the teacher share control of the design and management of learning activities, assessment criteria and social norms of the classroom. By negotiating the instructional goal and objectives with students, the teacher acknowledges the relevance of students' involvement in learning. Teachers can use students' reflections to design learning activities for innovation competence and create environments that encourage metacognition, self-analysis, regulation, reflection and selfawareness (Ernest 1995). In such environments, the teacher is seen by the students as a colearner, co-researcher and explorer as they engage in the tasks, and the teacher is resourceful and supportive of students' learning needs (Burgess and Addison 2007; Rutland and Barlex 2008). In this way, a safe and collaborative atmosphere is created where different students' learning approaches are valued.

In this current study, the CLES was adopted to evaluate students' perceptions of their classroom environments with respect to innovation competence using selected scales from the CLES (Taylor et al. 1995, 1997), namely, personal relevance, uncertainty and student negotiation. Below, we review relevant past studies on students' perception of their existing learning environments using the CLES. In order to compare perceptions, a 5-point scale has been interpreted as follows: scores between 1 and 2.4 were regarded as indicating a low perceived level of a constructivist approach, from 2.5 to 3.4 as a medium perceived level, and scores above 3.5 as a high perceived level. For a 7-point scale, scores between 1 and 3.4 were considered to indicate a low perceived level, between 3.5 and 4.4 as a medium perceived level, and scores above 4.5 as a high perceived level.

Research on constructivist learning environments has confirmed the factorial validity and reliability of the CLES in various contexts and countries (Aldridge et al. 2000; Beck et al. 2000; Kim et al. 1999; Kwan and Wong 2014; Lee and Taylor 2001; Ozkal et al. 2009; Taylor et al. 1997). For instance, the factorial validity and reliability of the CLES were established by Taylor et al. (1997) in Western Australia, with a sample of 494 13-year-old students in 41 science classes in 13 schools. Similarly, Aldridge et al. (2000) 
cross-validated the CLES also in Australia with a sample of 1081 science students in 50 classes. The CLES was validated as well in Korea (Kim et al. 1999; Lee and Taylor 2001) and Taiwan (Aldridge et al. 2000), and its cultural adaptability was shown by Lee and Taylor (2001) in their cross-national and longitudinal study in Korea. In the study by Aldridge et al. (2000), the original English version of the CLES was administered to 1081 science students in 50 classes in Australia, while a translated Chinese version was administered to 1879 science students in 50 classes in Taiwan. In both countries, the same factorial structure for the CLES and reasonable scale reliabilities were observed. In Singapore, Koh and Fraser (2014) used a modified version of the CLES and found good factorial validity and internal consistency reliability for both the actual and preferred learning environment were found.

Topolovčan et al. (2016) examined the perceptions of eighth-grade students $(N=1026)$ in primary and lower-secondary education in the Republic of Croatia regarding the characteristics and frequency of constructivist learning. On a five-point scale, Personal Relevance $(M=3.26)$, Uncertainty $(M=3.29)$ and Student Negotiation $(M=3.05)$ were perceived as present at around a medium level by the students.

Nix et al. (2005) used a modified version of the CLES to evaluate the impact of an innovative teacher development program called the Integrated Science Learning Environment model (ISLE) in high-school classrooms. They compared the perceptions of 445 students taught by 5 ISLE teachers in 25 classes and 328 students from 19 classes taught by 5 nonISLE science teachers in north Texas. On a five-point scale, the results showed a medium level of perceived Personal Relevance $(M=3.21)$, Uncertainty $(M=2.61)$ and Student Negotiation $(M=2.86)$.

Koh and Fraser (2014) studied 2216 secondary school students in Singapore in 82 business classes taught by preservice teachers regarding the constructive nature of their classroom environments. These teachers receive special training in how to create constructivist learning environments. The perceptions of the students taught by these trained teachers were compared with the perceptions of 991 secondary-school students in 32 business classes taught by traditional teachers. The perceptions of students about the constructivist nature of their actual classroom environments revealed a perceived medium level of both Personal Relevance $(M=3.23)$ and Student Negotiation $(M=3.33)$ medium scores, while Uncertainty $(M=3.48)$ was slightly above a medium level.

Kwan and Wong (2014) investigated secondary school students' perceptions of the constructivist nature of their learning environment in liberal studies $(N=967)$ in Hong Kong, and whether their perceptions were related to their critical thinking ability. The results showed high scores (on a 5-point scale) for Personal Relevance $(M=3.44)$, Uncertainty $(M=3.66)$ and Student Negotiation $(M=3.41)$. In general, students perceived their learning environments positively for the three variables.

Spinner and Fraser (2005), using a between-groups pretest-posttest design, analysed students' responses to their classroom environment, their attitudes and their conceptual development as related to mathematics education. The students in the experimental group scored Personal Relevance $(M=3.82)$ and Uncertainty $(M=3.55)$ highly, whereas Student Negotiation $(M=3.23)$ received a medium score. For the control group students, medium scores were reported for Personal Relevance $(M=3.81)$, Uncertainty $(M=3.05)$ and Student Negotiation $(M=2.55)$. The results showed an increment in scores for the experimental group relative to the control group, thereby supporting the effectiveness of the intervention.

Overall, the different studies using the CLES show that students typically perceive their environments to be moderately constructivist in nature (e.g. around or slightly above the 
neutral score). Student Negotiation was rated the lowest by the students in most studies, whereas Uncertainty received the highest scores. The intervention studies showed an increment in scores for all variables for the treatment group. However, because most of these studies were conducted in primary and secondary education, little is known about perceptions of these elements in higher education. Similarly, there has been no research that has examined relationships between scores on CLES scales and (self-) perceptions of innovation competence specifically. This study therefore investigated associations between constructivist learning environments as measured by CLES and innovation competence in the context of higher education.

\section{Research questions}

Building upon the reviewed literature, this study was designed to answer the following research questions:

1. How do Built Environment students perceive their own innovation competence?

2. What are students' perceptions of the existing learning environment with respect to innovation competence?

3. How do Built Environment students perceive the focus on innovation competence at the curriculum level and the relevance of teaching that aims to develop innovation competence in their major programme of study?

4. What is the association between students' perceptions of the learning environment and their perception of their own innovation competence?

\section{Method}

\section{Context and sample}

A survey was administered, via the various schools' heads of department, by email to students at eight Universities of Applied Sciences in the Netherlands where BE programs were offered. At Universities of Applied Sciences, Built Environment departments are required to develop students' innovation competence. Therefore, innovation competence is an end goal for all students following Built Environment programs. Innovation competence is considered one of the core competences necessary for career success in the professions addressed by the Built Environment discipline. Correspondingly, several educational steps have been taken towards realising the above objective in the various Built Environment departments.

An online questionnaire with an explanatory cover letter was emailed to a random sample of 400 year 1 to year 4 Built Environment students at the various schools. After an initial mailing, three follow-up reminder emails were sent. Overall, 130 students provided questionnaire responses, on which subsequent analyses were based. Of the 130 students, $27 \%$ were female. Students' ages ranged from 17 to 37 years $(M=21.5, S D=2.49)$. Students were distributed over the study years as follows: year $1, N=27$; year 2, $N=28$; year $3, N=32$; year 4, $N=43$. Study year represents the year in which students were enrolled at the time of completing the questionnaire. 


\section{Instrumentation}

The questionnaire mapped students' perceptions of the learning environment with respect to innovation competence development and students' self-perceived level of innovation competence. Also mapped were students' perceptions of the focus and relevance of innovation competence, as well as the association between the learning environments and students' self-perceived level of innovation competence. We created items using a 7-point response format of Strongly Disagree (1), Disagree, Somewhat Disagree, Neither Agree nor Disagree, Somewhat Agree, Agree and Strongly Agree (7), unless described otherwise.

\section{Innovation competence}

To measure students' self-perceived innovation competence, six scales were compiled using previously-validated scales from three different groups of authors in order to answer research question one. The scales measuring creativity, leadership and solving ambiguous problems were originally developed by Hurt et al. (1977) using US college students and public-school teachers. Out of 20 original items (displaying an overall Cronbach's alpha of 0.94), 13 items were selected for the current study (see Table 1). The energy scale and risk propensity scale were based on the work of Chell and Athayde (2009) using college students in the UK (with reported Cronbach's alphas of 0.75 and 0.58 , respectively). Lastly, the items on the creative self-efficacy scale (which had a Cronbach's alpha of 0.83 in their study) were taken from Tierney and Farmer (2002). See Table 1 below for the newly-compiled innovation competence scales.

Exploratory factor analysis on the data from the present study suggested a 6-factor solution. In this analysis, a varimax rotation was used, eigenvalues were set to 1 or higher, and factor loadings were inspected for meeting the 0.35 threshold on their expected scales and no high loadings on other scales. This solution followed the expected pattern, even though some items had to be removed for not meeting the criteria.

In the end, seven items measured Creativity, with a Cronbach's alpha of 0.90, while three items measured Creative Self-efficacy, with a Cronbach's alpha of 0.83 . Three items measured students' perceptions of their Leadership, with a Cronbach's alpha of 0.77. The Energy scale was measured with seven items having a Cronbach's alpha of 0.81 . Four items measured students' perceptions of their Risk Propensity, with a Cronbach's alpha of 0.67. The Solving Ambiguous Problems scale was measured with just 2 items, with a Cronbach's alpha of 0.79 . All variables correlated significantly one with another, but the correlations were sufficiently low to justify the use of separate scales (see Table 5, variables 4-9, for the correlation matrix).

\section{Learning environment}

For the purpose of answering research question two, three constructs were selected from the CLES. The Personal relevance, Uncertainty and Student Negotiation scales from the Constructivist Learning Environment Survey (CLES; Taylor et al. 1997) were used to assess the explicitness of and focus on learning activities in the classroom environment that were supportive of innovation competence (see Table 2). Taylor et al. (1997) reported Cronbach's alpha of above 0.70 for all of the scales in their study. 


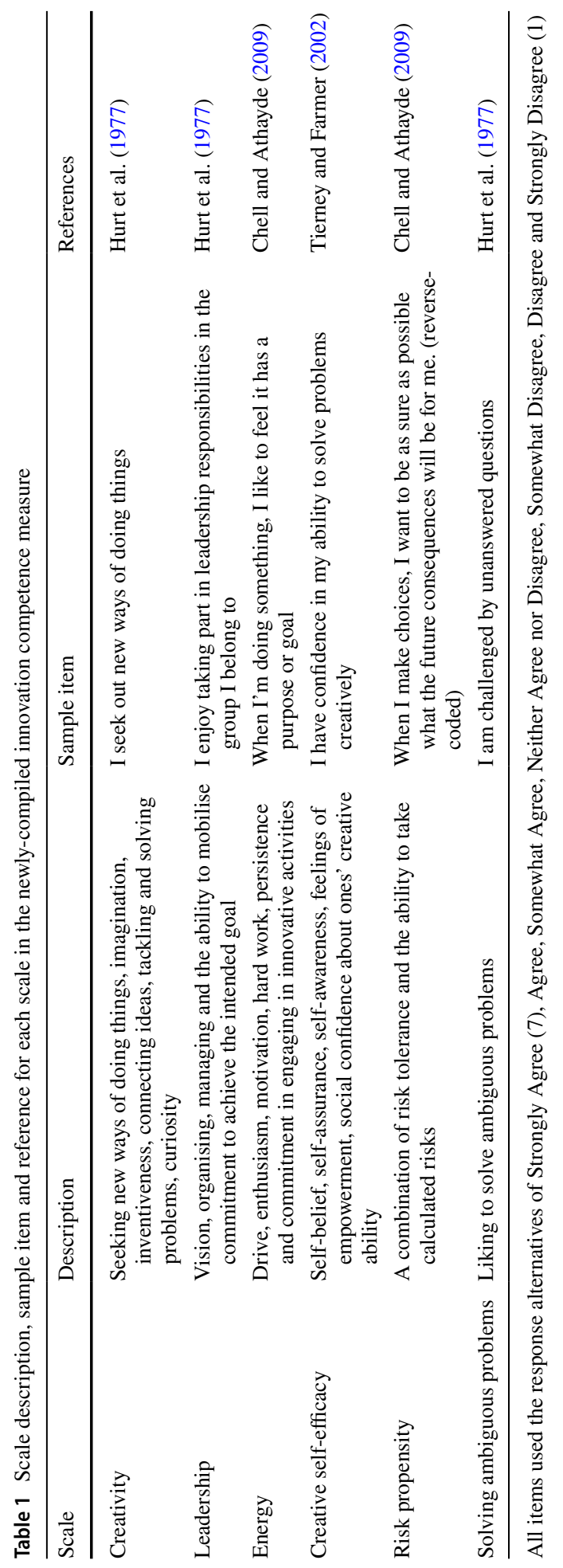




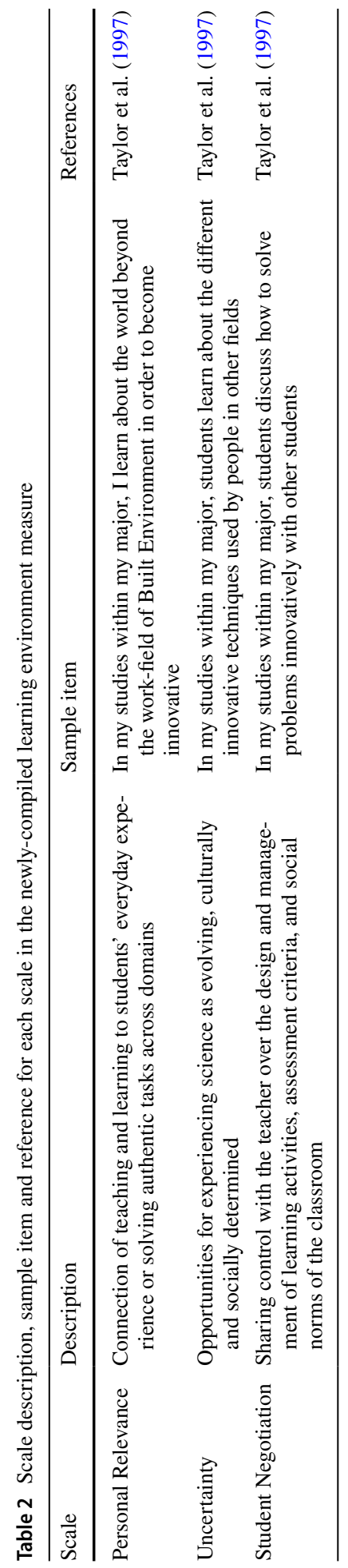


A number of items were selected and reframed to fit the purpose and the context of our research. Two new items were added to the Personal Relevance scale. Exploratory factor analysis (EFA) was conducted to analyse construct validity. A principal axis factoring (PAF) and oblimin rotation were used. Because three scales were expected, the analysis was constrained to three factors. All items loaded meaningfully on their respective scale.

Personal Relevance in our study comprised four items, with a Cronbach's alpha of 0.87. Uncertainty consisted of five items, with a Cronbach alpha of 0.92. Student Negotiation consisted of just two items, with a Cronbach's alpha of 0.85. As can be seen in Table 5, the three CLES scales (variables 1-3 in the Table) correlated statistically significantly with each other, though to such a level that they can be considered as independent scales.

\section{Relevance of innovation competence: Focus on innovation competence at the curriculum level and relevance of teaching for innovation competence}

Previous research has revealed that educators have made serious efforts to stimulate innovation competence by focusing on developing students' innovation competence through teaching (Beghetto and Kaufman 2013). For this reason, we sought to know via research question 3 how students perceived the focus on innovation competence by their teachers in their school and its relevance.

The scale related to Focus on Innovation Competence at the Curriculum Level consisted of four items, created to measure a school's explicit focus on innovation competence at the school/curriculum level. Reliability in terms of Cronbach's alpha was 0.90. A sample item in the scale was 'In my school, innovation competence is an end goal'. Factor analysis revealed a one-factor solution, accounting for approximately $74 \%$ of the common-factor variance, with all 4 items loading meaningfully on the factor.

To measure perceptions of the Relevance of Teaching for Innovation Competence, students were asked to respond to one item, with response options ranging from very irrelevant (1) to very relevant (7). The item asked students whether they considered being taught about how to become innovative relevant. Also, students were asked to indicate in a single binary item (Yes or No) if they were explicitly being taught by their teachers to become innovative in their major course of studies. Respondents who answered Yes were asked to further specify the subject/course/module name and study year of the course. This approach has also been used by other researchers investigating innovation competence in the curriculum (Adams 2013; Aish 2014; Shaheen 2011).

\section{Data analysis}

The data collected through the questionnaires from students were organised, presented in tables and then analysed statistically by calculating means and standard deviations for the purpose of answering research questions 1 to 3 . Correlation and regression analyses were conducted for the purpose of answering research question 4. In the regression analyses, the six self-perceived competencies were used as dependent scales and the learning environment variables as the independent variables. In addition, we also computed an overall innovation competence score as the average of the six specific competencies, and this variable was also used in the regression analyses. Correlations were interpreted as follows (Cohen 1988): $r=0.10$ to 0.29 or $r=-0.10$ to -0.29 as small; $r=0.30$ to 0.49 or $r=-0.30$ to -0.4 .9 as medium; and $r=0.50$ to 1.0 or $r=-0.50$ to -1.0 as large. 
Table 3 Average scale means and standard deviations of scores for innovation competence

\begin{tabular}{lllllll}
\hline Statistics & Creativity & Leadership & Energy & $\begin{array}{l}\text { Creative self- } \\
\text { efficacy }\end{array}$ & Risk propensity & $\begin{array}{l}\text { Solving } \\
\text { ambiguous } \\
\text { problems }\end{array}$ \\
\hline$M$ & 5.51 & 4.99 & 5.65 & 5.11 & 4.79 & 4.77 \\
$S D$ & 0.86 & 1.07 & 0.81 & 1.07 & 1.06 & 1.26 \\
\hline
\end{tabular}

$N=130$

Table 4 Average scale means and standard deviations of scores for the perceived learning environment

\begin{tabular}{llll}
\hline Statistics & Personal relevance & Uncertainty & $\begin{array}{l}\text { Student } \\
\text { negotia- } \\
\text { tion }\end{array}$ \\
\hline$M$ & 3.83 & 4.02 & 4.15 \\
$S D$ & 1.36 & 1.44 & 1.59 \\
\hline
\end{tabular}

$N=130$

\section{Results}

\section{Students' perception of their own innovation competence (research question 1)}

The results relating to students' perception of their own innovation competence are categorised under the six separate constructs to which the scales refer: creativity, leadership, energy, creative self-efficacy, risk propensity and solving ambiguous problems. The results as presented in Table 3 show that students on average perceived their innovation competence reasonably highly for all the six scales. However, students reported a somewhat higher score for energy, creativity and creative self-efficacy, than for solving ambiguous problems, risk propensity and leadership, which were rated lower. The standard deviations suggested considerable differences on each aspect between students.

\section{Students' perceptions of the learning environment (research question 2)}

Results regarding students' perceptions of the learning environment presented in Table 4 show that students on average perceived their learning environment as moderately constructivist. All scores ranged around the midpoint of 4 on a scale of 1 to 7 , with Personal Relevance rated as the lowest, while Student Negotiation was rated the highest.

\section{Students' perceptions of the relevance of teaching for innovation competence development (research question 3)}

Students' perceptions of the focus on innovation competence at the school/curriculum level, $(M=4.17, S D=1.49)$ showed a moderate perceived focus on innovation competence, on a scale of 1 to 7 . Regarding the question of whether teaching students to become innovative is relevant, students reported on average a view of it as somewhat relevant $(M=4.69, S D=1.40)$. Students were also asked to indicate on a single item scale if they 


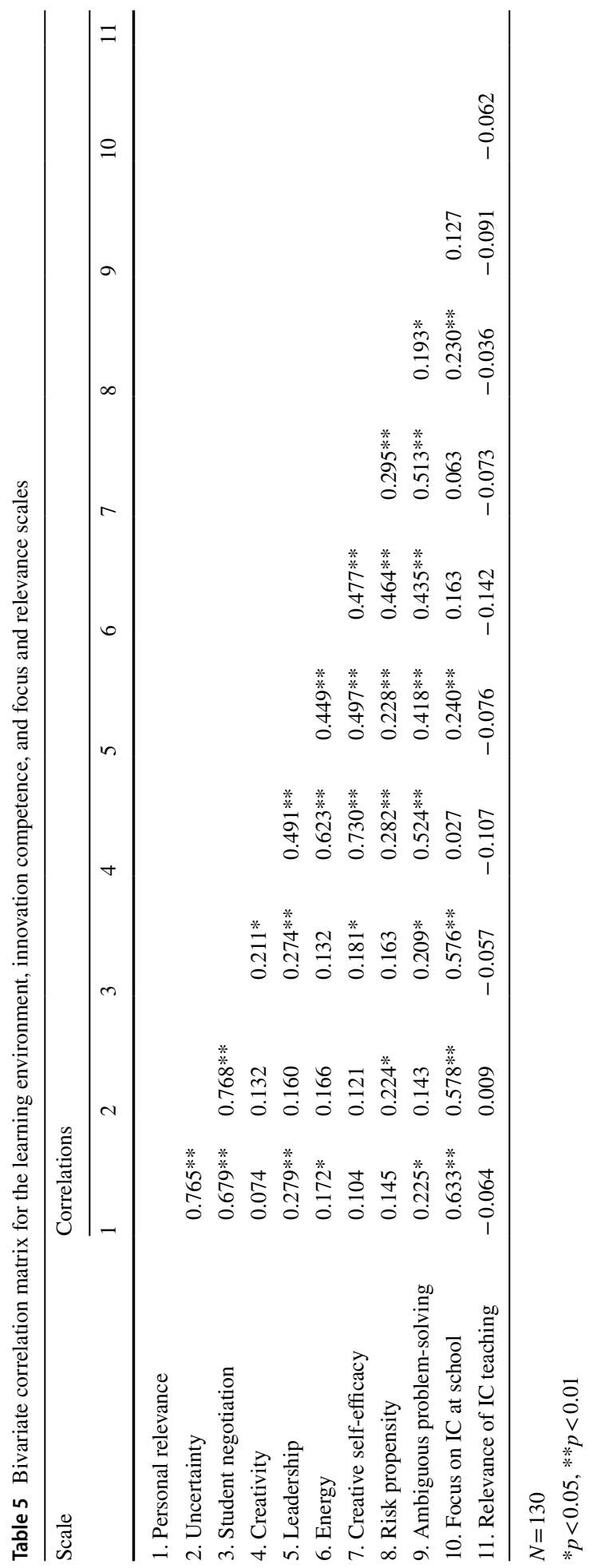


were intentionally taught by their teachers to become innovative in their major course (Yes or No). Of the 130 participants, 51 students (39.2\%) indicated that there was indeed an explicit teaching focus on development of innovation competence, whereas $79(60.8 \%)$ indicated no explicit teaching focus. Of the 51 students who indicated an explicit teaching focus on innovation competence, only 27 further specified a course or module that had an explicit focus on students' innovation competence development at their school. Some examples of modules specified were a 3rd year architectural module focused on developing concepts for zero energy utilitarian building and a 2 nd year renovation project module in which students were asked to design new functions and building methods. Other examples mentioned by students were broad subject areas such as structural design, building physics and building technology.

\section{Associations between perceptions of the learning environment and perceived innovation competence (research question 4)}

We used multiple regression analysis to investigate relationships between the perceived learning environment scales (Personal Relevance, Uncertainty, Student Negotiation) and the self-perceived innovative competence scales (Creativity, Leadership, Energy, Creative Self-Efficacy, Risk Propensity and Solving Ambiguous Problems). The perceived level of Focus on Innovation Competence at School and the Relevance of Teaching for Innovation Competence Development were also tested as predictors of self-perceived innovation competence. Firstly, we discuss the results of the correlation analysis presented in Table 5.

As can be seen in Table 5, all six innovation competence scales were positively and statistically significantly correlated with one or more of the three constructivist learning environment variables.

In order to determine the joint and unique predictive contribution of the learning environment, focus and relevance variables to students' total innovation competence and its individual components, seven stepwise multiple regression analyses were conducted. The first analysis focused on students' combined innovation competence (average of 6 competences), while the second to the seventh steps calculated the joint effects of each learning environment, focus and relevance variable on each of students' separate innovation competences.

The first step revealed a significant relationship for Student Negotiation, which accounted for $5.7 \%$ (5.0\% adjusted) of the variance in students' total Innovation Competence scores. This means that the more that students perceived Negotiation in their learning environment, the more they perceived themselves overall as having Innovation Competence. The second analysis indicated a significant relationship for Student Negotiation, which accounted for $4.5 \%$ (3.7\% adjusted) of the variance in Creativity scores. Thus, the more that students perceived negotiation in their learning environment, the more they perceived themselves overall as creative. The third analysis indicated a significant association for Personal Relevance, which accounted for 7.8\% (7.1\% adjusted) of the variance in Leadership scores. The more that students perceived learning to be personally relevant in their learning environment, the more they perceived themselves overall to take a leadership role. The fourth analysis indicated a significant association for Personal Relevance, which accounted for $3.0 \%$ (2.2\% adjusted) of the variance in Energy scores. This means that the more that students perceived learning to be personally relevant in their learning environment, the more they perceived themselves to expend energy in learning. The fifth analysis indicated a significant relationship for Student Negotiation, which accounted for 
$3.3 \%$ (2.5\% adjusted) of the variance in Creative Self-efficacy scores. Hence, the more that students perceived negotiation in their learning environment, the higher they rated their creative self-efficacy. The sixth analysis indicated a significant association for Focus on Innovation Competence at School, which accounted for 5.3\% (4.6\% adjusted) of the variance in Risk Propensity scores. The more that students perceived there to be a focus on innovation competence development in their learning environment, the more willing they were to take risks. The seventh analysis, finally, indicated a significant relationship for Personal Relevance, which accounted for 5.1\% (4.3\% adjusted) of the variance in scores for solving Ambiguous Problems. The more that students perceived learning to be personally relevant in their learning environment, the more they perceived themselves overall as competent in solving ambiguous problems. All reported associations were statistically significant at the 0.05 level.

\section{Discussion and conclusion}

The main goal of this study was to map students' perceptions of the extent to which Built Environments curricula were directed towards and resulted in the development of innovation competence by measuring students' self-perceived innovation competence, the relevance of teaching for innovation competence and perceptions of the learning environment. The results showed that students perceived that the learning environments at the Universities of Applied Sciences were only to some degree directed towards development of students' innovation competence, which might indicate that teachers were often concerned with this competence in an implicit fashion. Although students perceived learning to become innovative as somewhat relevant, and rated their innovation competence relatively high, their perceptions of the learning environment showed a somewhat lower perception of the personal relevance of the teaching and learning activities in their school environments. These results suggest that Universities of Applied Sciences can potentially enhance their students' innovation competence by implementing constructivist learning environments principles more explicitly.

Students perceived themselves on average to be sufficiently competent in accomplishing innovation-related tasks; higher scores were reported for creativity, leadership, energy and creative self-efficacy, but lower scores for risk propensity and ability to solve ambiguous problems. High scores on the innovation competence scales, according to Chell and Athayde (2009), are likely to represent students' intentions to become future innovators. The relatively lower scores for risk propensity in our study could be explained by a lack of formal teaching mechanisms for risk propensity in the domains of Built Environments education. Chell and Athayde (2009) concluded that the lack of teaching risk of propensity in school most likely would reflect students' interest and intelligence and/or their socioeconomic background. It is worth mentioning that risk propensity was a weak scale in the original instrument of Chell and Athayde (2009), with an alpha coefficient of 0.58 . The same applied to our study, for which risk propensity was also a relatively weak scale, with a Cronbach's alpha of 0.67. Risk propensity has many dimensions (Chell and Athayde 2009); hence it is suggested that education should focus on these different dimensions, which include: seeking sensation; avoiding risk; and taking calculated risks. Taking calculated risks involves recognising inherent risks in what one does, but also being able to take relevant steps to reduce those risks. Risk-adaptors or -absorbers recognise the risks in what they do, but either naturally or through training learn to bear those risks. Considering the 
complexity of risk propensity and its typologies in educational settings, teaching students how to take, bear, analyse and absorb risk is very relevant but difficult to realise. Further research could be conducted to gain understanding into what really constitutes risk propensity and its teaching.

In a way, this research re-establishes and joins the array of studies that have confirmed the effectiveness of using students' views to understand learning environments (den Brok et al. 2006; Fraser 2007; Koh and Fraser 2014; Kwan and Wong 2014; Nix et al. 2005). Students generally were moderately positive about the constructivist nature of the learning environment for innovation competence in their schools with regard to personal relevance, uncertainty and student negotiation, thereby replicating prior studies (Koh and Fraser 2014; Kwan and Wong 2014; Nix et al. 2005; Spinner and Fraser 2005; Topolovčan et al. 2016). The highest score reported in this study was for student negotiation, which did not align with the results of past studies. Student negotiation is the degree to which students share control with the teacher over the design and management of learning activities, assessment criteria and social norms of the classroom. One possible explanation for this high score for student negotiation could be cultural. The Netherlands is a country with low power distance compared with most other countries (Hofstede et al. 2010). Power distance is the extent to which the less powerful members of organisations and institutions (like the schools) accept and expect that power is distributed unequally. This could mean that students in the Netherlands consider it normal to debate or negotiate relatively freely with their teachers. It might not be surprising, therefore, that participants in this study scored student negotiation higher than in studies in other countries, suggesting that teacher involve students in the design and management of learning activities. Another potential explanation is that students in our study were enrolled in higher education, whereas most other studies were undertaken in secondary education. It might be expected that students in higher education are given more responsibility over their learning process, as well as in the classroom.

In this study, uncertainty was rated relatively high, which is consistent with prior studies (Koh and Fraser 2014; Kwan and Wong 2014; Nix et al. 2005; Topolovčan et al. 2016). Interestingly, the students in our study scored personal relevance lowest, which is contrary to the findings of Kwan and Wong (2014), Nix et al. (2005) and Topolovčan et al. (2016), but consistent with the findings of Koh and Fraser (2014). These differences could be attributed to the differences in educational contexts (secondary versus higher education). University students are often older and therefore could be more conscious and more realistic about their perceptions of their learning environments compared with primary and secondary students. This could suggest the need for further studies of these variables in the context of higher education.

\section{Understanding the association between innovation competence and learning environment}

There was a statistically-significant correlation as expected between scores for each of the constructivist learning environment variables (Personal Relevance, Uncertainty, Student Negotiation) and each of the six innovation competence variables. Multiple regression analyses showed that student negotiation was the only significant predictor of students' overall perceived innovation competence. Our study suggests that, when teachers involve students in the design and management of learning, there is created a learning environment that supports students' creativity and innovative thinking, rather than constraining 
it. Unfortunately, no other studies have investigated at this relation in the context of higher education. Therefore, comparing our results with past studies is not possible.

\section{Limitations}

There were some limitations in the present study that should be addressed in future research. First, this study was limited in the sense that we only investigated a set of factors that were proposed to be linked to innovation competence and its teaching. However, as found in other studies, innovation competence is sometimes affected by other variables, such as personality traits (Fisher et al. 2011), the physical environment and teachers' teaching style. While this study did not examine the relationship between personality, the physical environment, teachers' teaching style and innovation competence, future studies could examine these relationships further.

Second, although our findings are in line with previous studies about how individuals perceive their innovative ability in general (Chell and Athayde 2009; Dyer et al. 2009; Hurt et al. 1977; Tierney and Farmer 2002), it says very little about the actual level of mastery, as students might over- or under-estimate themselves. To understand whether Built Environments students have developed innovation competence, there is a need for further studies that include, besides elements that were already part of the present study, validating the construct of innovation competencies by using larger sample sizes and developing design principles for creating teaching interventions intentionally dedicated to the development of innovation competence.

Finally, this study was conducted in a single country with a distinct culture and in one domain of study, which could limit its generalisability. Therefore the generalisability of the results of this study needs to be ascertained through future research in other countries with different educational cultures and fields of studies.

\section{Recommendations}

For the improvement of innovation competence development in the Built Environment Engineering curriculum, the following actions are recommended based on the results of this study. First, the low scores for personal relevance compared to previous studies using the CLES in primary and secondary education suggest that more attention is needed to this dimension of the learning environment. This result requires teaching and learning to be better connected to students' everyday out-of-school experiences by engaging them in authentic activities, using open-ended tasks and using real-world problems (Jonassen 1994; Lim and Sato 2006).

Second, a more-explicit focus on innovation competence is needed, as suggested by students' perceptions of the focus on innovative competence at the curriculum/school level, with approximately $61 \%$ of the respondents perceiving no explicit focus on innovation competence in their curriculum. A portion of the curriculum should intentionally be dedicated to the development of students' innovation competence. This approach would help to consciously direct teaching to the development of students' innovative mindset and problem-solving in the context of discipline-based curricula. This approach is often avoided by educators because of the significant volume of discipline-specific knowledge to be taught, and the difficulties of educators in integrating competencies into the engineering curriculum. However, previous studies (e.g. Swartz and Parks 1994) have demonstrated the effectiveness of such an approach. 
Acknowledgements This research was financially supported by Hanze University of Applied Science Groningen and The Netherlands Organisation for Scientific Research of the Netherlands (Grant No. 023.006.028).

Open Access This article is distributed under the terms of the Creative Commons Attribution 4.0 International License (http://creativecommons.org/licenses/by/4.0/), which permits unrestricted use, distribution, and reproduction in any medium, provided you give appropriate credit to the original author(s) and the source, provide a link to the Creative Commons license, and indicate if changes were made.

\section{References}

Adams, J. W. (2013). A case study: Using lesson study to understand factors that affect teaching creative and critical thinking in elementary classrooms. Unpublished doctoral dissertation. Available from ProQuest Dissertations and Thesis database. (UMI No. 1356692081).

Aish, D. (2014). Teachers' beliefs about creativity in elementary classrooms. Unpublished doctoral dissertation. Available from ProQuest Dissertations and Thesis database. (UMI No. 1566193678).

Aldridge, J. M., \& Fraser, B. J. (2011). Effects and determinants of outcomes-focused learning environments. Curriculum and Teaching, 26(1), 5-31.

Aldridge, J. M., Fraser, B. J., Taylor, P. C., \& Chen, C. C. (2000). Constructivist learning environments in a cross-national study in Taiwan and Australia. International Journal of Science Education, 22, 37-55.

Antonietti, A., Colombo, B., \& Pizzingrilli, P. (2011). The WCR model of creativity: From concept to application. The Open Education Journal, 4, 80-89.

Bandura, A. (1997). Self-efficacy: The exercise of control. Chicago: Macmillan.

Beck, J., Czerniak, C. M., \& Lumpe, A. T. (2000). An exploratory study of teachers' beliefs regarding the implementation of constructivism in their classroom. Journal of Science Teacher Education, 11, 323-343.

Beghetto, R. (2010). Creativity in the classroom. In J. C. Kaufman \& R. J. Sternberg (Eds.), The Cambridge handbook of creativity (pp. 447-459). New York: Cambridge University Press.

Beghetto, R. A., \& Kaufman, J. C. (2013). Fundamentals of creativity. Educational Leadership, 70, 10-15.

Beghetto, R. A., \& Kaufman, J. C. (2014). Classroom contexts for creativity. High Ability Studies, 25(1), 53-69.

Bel, R. (2010). Leadership and innovation: Learning from the best. Global Business and Organizational Excellence, 29(2), 47-60.

Bell, L., \& Aldridge, J. (2014). Student voice, teacher action research and classroom research (Advances in Learning Environments Research series). Rotterdam: Sense Publishers.

Brookes, S., Moseley, A., \& Underwood, S. (2012). Contextual games: Pervasive learning activities in enterprise education (a case study). In ISBE conference proceedings: 2012 Dublin conference (CD-ROM).

Burgess, L., \& Addison, N. (2007). Conditions for learning: Partnerships for engaging secondary pupils with contemporary art. JADE, 26(2), 185-198.

Campbell, W. K., Goodie, A. S., \& Foster, J. D. (2004). Narcissism, confidence, and risk attitude. Journal of Behavioral Decision Making, 17, 297-311.

Chan, S., \& Yuen, M. (2014). Personal and environmental factors affecting teachers' creativity-fostering practices in Hong Kong. Thinking Skills and Creativity, 12, 69-77.

Chell, E., \& Athayde, R. (2009). The identification and measurement of innovative characteristics of young people. London: NESTA.

Cohen, J. (1988). Statistical power analysis for the behavioral sciences. Hillsdale, NJ: Erlbaum.

Craft, A. (2011). Creativity and education futures: Learning in a digital age. Stoke-on-Trent: Trentham Books.

Dalke, A. F., Cassidy, K., Grobstein, P., \& Blank, D. (2007). Emergent pedagogy: Learning to enjoy the uncontrollable - and make it productive. Journal of Educational Change, 8(2), 111-130.

den Brok, P., Bergen, T., \& Brekelmans, M. (2006). Convergence and divergence between teachers' and students' perceptions of instructional behaviour in Dutch secondary education. In D. L. Fisher \& M. $\mathrm{S}$. Khine (Eds.), Contemporary approach-es to research on learning environments: World views (pp. 125-160). Singapore: World Scientific.

Dillon, P., Craft, A., Best, P., Rigby, A., \& Simms, K. (2007). Turning peases west inside out: Flexible educational environments for developing possibilities and pedagogies. Sunderland: Creative Partnerships Durham. 
Dorman, J., \& Fraser, B. J. (2009). Psychosocial environment and affective outcomes in technology-rich classrooms: Testing a causal model. Social Psychology of Education, 12(1), 77-99.

Dyer, J. H., Gregersen, H. B., \& Christensen, C. M. (2009). The innovator's DNA. Harvard Business Review, 87(12), 61-67.

Ernest, P. (1995). The one and the many. In L. Steffe \& J. Gale (Eds.), Constructivism in education (pp. 459-486). Hillsdale, NJ: Lawrence Erlbaum Associates Inc.

Ertmer, P. A., \& Newby, T. J. (1993). Behaviorism, cognitivism, constructivism: Comparing critical features from an instructional design perspective. Performance Improvement Quarterly, 26(2), 43-71.

Fasko, D. (2001). Education and creativity. Creativity Research Journal, 13(3-4), 317-327.

Fisher, E., Biviji, M., \& Nair, I. (2011). New perspectives on teaching innovation to engineers: An exploration of mental models of innovation experts. In Proceedings of the 2011 ASEE annual conference and exposition, Vancouver, BC.

Fraser, B. J. (2007). Classroom learning environments. In S. K. Abell \& N. G. Lederman (Eds.), Handbook of research on science education (pp. 103-124). Mahwah, NJ: Lawrence Erlbaum.

Fraser, B. J. (2012). Classroom learning environments: Retrospect, context and prospect. In B. J. Fraser, K. G. Tobin, \& C. J. McRobbie (Eds.), Second international handbook of science education (pp. 1191-1239). New York: Springer.

Halsey, K., Jones, M., \& Lord, P. (2006). What works in stimulating creativity amongst socially excluded young people. http://www.nfer.ac.uk/nfer/publications/NES01/NES01.pdf. Accessed 17 Sept 2018.

Hofstede, G., Hofstede, G. J., \& Minkov, M. (2010). Cultures and organizations: Software of the mind (Rev. 3rd ed.). New York: McGraw-Hill. [For translations, see www.geerthofstede.nl and "our books"]. Accessed 17 Sept 2018.

Honebein, P. (1996). Seven goals for the design of constructivist learning environments. In B. Wilson (Ed.), constructivist learning environments (pp. 17-24). Saddle Brook, NJ: Educational Technology Publications.

Hunter, S. T., Cushenbery, L., \& Friedrich, T. (2012). Hiring an innovative workforce: A necessary yet uniquely challenging endeavor. Human Resource Management Review, 22(4), 303-322.

Hurt, H. T., Joseph, K., \& Cook, C. D. (1977). Scales for the measurement of innovativeness. Human Communication Research, 4(1), 58-65.

Jackson, P. W., \& Messick, S. (1967). Creativity and learning. Boston, MA: Houghton Mifflin.

Jonassen, D. (1994). Thinking technology. Educational Technology, 34(4), 34-37.

Jonassen, D. H. (1999). Designing constructivist learning environments. In C. M. Reigeluth (Ed.), Instructional-design theories and models: A new paradigm of instructional theory (pp. 215-240). New York: Lawrence Erlbaum Associates.

Keller, R. T. (2012). Predicting the performance and innovativeness of scientists and engineers. Journal of Applied Psychology, 97(1), 225-233.

Kim, H. B., Fisher, D. L., \& Fraser, B. J. (1999). Assessment and investigation of constructivist science learning environments in Korea. Research in Science and Technological Education, 17, 239-249.

Koh, N. K., \& Fraser, B. J. (2014). Learning environment associated with the use of mixed-mode delivery model among secondary business studies students in Singapore. Learning Environments Research, 17, 157-171.

Kwan, Y., \& Wong, A. F. L. (2014). The constructivist classroom learning environment and its associations with critical thinking ability of secondary school students in liberal studies. Environmental Education Research, 17, 157-171.

Lee, S., \& Taylor, P. (2001). The cultural adaptability of the CLES: A Korean perspective. In Paper presented at the annual meeting of the Australian Association for Research in Education, Fremantle, Australia.

Li, Z., Cheng, Y., \& Liu, C. (2012). A constructionism framework for designing game-like learning systems: Its effect on different learners. British Journal of Educational Technology, 44(2), 208-224.

Lim, Y. K., \& Sato, K. (2006). Describing multiple aspects of use situation: Applications of design information framework (DIF) to scenario development. Design Studies, 27, 57-76.

Martin-Dunlop, C., \& Fraser, B. J. (2008). Learning environment and attitudes associated with an innovative course designed for prospective elementary teachers. International Journal of Science and Mathematics Education, 6, 163-190.

Nix, R. K., Fraser, B. J., \& Ledbetter, C. E. (2005). Evaluating an integrated science learning environment using the constructivist learning environment survey. Learning Environments Research, 8, $109-133$.

Ozkal, K., Tekkaya, C., Cakiroglu, J., \& Sungur, S. (2009). A conceptual model of relationships among constructivist learning environment perceptions, epistemological beliefs, and learning approaches. Learning and Individual Differences, 19, 71-79. 
Price, L. L., \& Ridgway, N. M. (1983). Development of a scale to measure use innovativeness. Advances in Consumer Research, 10(1), 679-684.

Ragusa, G. (2011). Engineering creativity and propensity for innovative thinking in undergraduate and graduate students. In Paper presented at the 2011 annual conference and exposition, Vancouver.

Richardson, C., \& Mishra, P. (2018). Learning environments that support student creativity: Developing the SCALE. Thinking Skills and Creativity, 27, 45-54.

Robinson, K. (2011). Out of our minds. West Sussex: Capstone Publishing.

Rutland, M., \& Barlex, D. (2008). Perspectives on pupil creativity in design and technology in the lower secondary curriculum in England. International Journal of Technology and Design Education, 18, $139-165$.

Scott, S. G., \& Bruce, R. A. (1994). Determinants of innovative behavior: A path model of individual innovation in the workplace. Academy of Management Journal, 37(3), 580-607.

Shaheen, R. (2011). The place of creativity in Pakistani primary education system: An investigation into the factors enhancing and inhabiting primary school children's creativity. Unpublished doctoral dissertation, University of Birmingham. Retrieved from http://files.eric.ed.gov/fulltext/ED522273.pdf. Accessed 17 Sept 2018.

Spinner, H., \& Fraser, B. J. (2005). Evaluation of an innovative mathematics program in terms of classroom environment, student attitudes, and conceptual development. International Journal of Science and Mathematics Education, 3, 267-293.

Swartz, R., \& Parks, S. (1994). Infusing the teaching of critical and creative thinking into content instruction: A lesson design handbook for the elementary grades. Pacific Grove, CA: Critical Thinking Press and Software.

Tabak, F., \& Barr, S. H. (1999). Propensity to adopt technological innovations: The impact of personal characteristics and organizational context. Journal of Engineering and Technology Management, 16, 247-270.

Taylor, P., Dawson, V., \& Fraser, B. (1995). A constructivist perspective on monitoring classroom learning environments under transformation. In Paper presented at the Annual Meeting of the American Educational Research Association, San Francisco, CA.

Taylor, P., Fraser, B., \& Fisher, D. (1997). Monitoring constructivist classroom learning environments. International Journal of Educational Research, 27(4), 293-302.

Tidd, J., \& Bessant, J. (2009). Managing innovation (4th ed.). Chichester: Wiley.

Tierney, P., \& Farmer, S. M. (2002). Creative self-efficacy: Its potential antecedents and relationship to creative performance. Academy of Management Journal, 45(6), 1137-1148.

Tierney, P., \& Farmer, S. M. (2011). Creative self-efficacy development and creative performance over time. Journal of Applied Psychology, 96, 277-293.

Topolovčan, T., Matijević, M., \& Dumančić, M. (2016). Some predictors of constructivist teaching in elementary education. Croatian Journal of Education, 18(1), 193-212.

Wagner, T. (2010). The global achievement gap: Why even our best schools don't teach the new survival skills our children need-and what we can do about it. New York: Basic Books.

Wang, P., Rode, J. C., Shi, K., Luo, Z., \& Chen, W. (2013). A workgroup climate perspective on the relationships among transformational leadership, workgroup diversity, and employee creativity. Group Organization Management, 38(3), 334-360.

West, M. A. (2002). Sparkling fountains or stagnant ponds: An integrative model of creativity and innovation implementation in work groups. Applied Psychology: An International Review, 51(3), 355-424.

West, M. A., \& Farr, J. L. (Eds.). (1990). Innovation and creativity at work. Chichester: Wiley.

Wood, R., \& Ashfield, J. (2008). The use of the interactive whiteboard for creative teaching and learning in literacy and mathematics: A case study. British Journal of Educational Technology, 39(1), 84-96.

Publisher's Note Springer Nature remains neutral with regard to jurisdictional claims in published maps and institutional affiliations. 